\title{
Definite Residual Metabolic Tumor Activity by PET
}

National Cancer Institute

\section{Source}

National Cancer Institute. Definite Residual Metabolic Tumor Activity by PET. NCI

Thesaurus. Code C116100.

A finding of strong focal metabolic activity at the primary or nodal sites that is greater than liver uptake, as detected by FDG-PET. 